\title{
Creating opportunities for interprofessional, community-based education for the undergraduate dental therapy degree in the School of Health Sciences, University of KwaZulu-Natal, South Africa: Academics' perspectives
}

\author{
I Moodley, B Dent Ther, MSc (Dent); S Singh, PhD \\ Discipline of Dentistry, School of Health Sciences, University of KwaZulu-Natal, Durban, South Africa
}

Corresponding author: I Moodley (moodleyil@ukzn.ac.za)

\begin{abstract}
Background. Interprofessional education (IPE) provides opportunities for students from two or more health profession disciplines to learn with, from and about each other, to foster collaborative practice in the future, when health professionals are expected to work in healthcare teams. While there are many documented examples of IPE among student health professionals in the literature, dental therapy student participation in IPE has been excluded. Objectives. To explore the opportunities for dental therapy students to participate in collaborative interprofessional, community-based initiatives by engaging with academics in the School of Health Sciences at the University of KwaZulu-Natal.

Methods. This qualitative study used audiotaped interviews and focus-group discussions with a purposively selected sample of academics, and the results were thematically analysed.

Results. The academics noted several opportunities for dental therapy students to participate in interprofessional, community-based education on various platforms, including school, primary healthcare and other community-based settings. Barriers that may hamper implementation include finding a common time for IPE in the uniprofessional curricula, matching student numbers and lack of staff support.

Conclusion. The study findings revealed that opportunities exist for community-based IPE interventions for dental therapy students. However, both the creation and implementation of interprofessional interventions require individual lecturers to act as drivers across all disciplines.
\end{abstract}

Afr J Health Professions Educ 2018;10(1):19-25. DOI:10.7196/AJHPE.2018.v10i1.974

Health professionals' education is currently undergoing a major transformation, in which community-based and interprofessional education (IPE) are being integrated into curricula, to align student training to meet the needs of the communities they are likely to serve and the health systems within which they will work. ${ }^{[1]}$ IPE is an innovative learning strategy that breaks down the professional silos that commonly exist in training institutions. ${ }^{[2]}$ This strategy provides opportunities for students from two or more health profession disciplines to learn with, from and about each other, or to collaborate to provide promotive, preventive, curative and rehabilitative services to patients, in an attempt to enable students to work effectively in healthcare teams upon graduation. ${ }^{[2,3]}$

There are many documented examples of IPE being practised among student health professionals in various institutions, both in South Africa (SA) and internationally. However, participation by students in the field of dentistry has been minimal or non-existent. ${ }^{[4]}$ Students in the dentistry field include dentists, dental therapists and oral hygienists in training, and their omission from interprofessional learning activities is based on the presumption that oral health is separate from general health, ${ }^{[4]}$ although it is integral to general health and wellbeing. ${ }^{[5]}$ Routine dental examinations can result in the early detection of certain systemic diseases that manifest in the oral cavity, making dental personnel important members of a team that manages the overall health of a patient through screening, diagnosis and referral. ${ }^{[4]}$
Although highly prevalent, oral diseases are largely preventable, and share common risk factors, including an unhealthy diet, excessive tobacco use and harmful alcohol consumption, with other leading non-communicable diseases (NCDs) such as diabetes, cardiovascular diseases, respiratory diseases and certain forms of cancer ${ }^{[5,6]}$ Integrating oral health-promotion strategies and programmes with broader programmes in preventing and controlling NCDs can lead to better health outcomes. ${ }^{[7]}$ Therefore, collaborating and networking with other healthcare professionals is essential for dental personnel, and should begin in their training, to develop the skills of collaborative practice and holistic patient management. Moreover, SA, specifically KwaZulu-Natal Province, has a considerable burden of disease, including oral conditions, which impacts on the under-resourced health system. ${ }^{[8]}$

The University of KwaZulu-Natal (UKZN) is responsible for training health professionals in the province, and contributes significantly to a workforce that meets the healthcare needs of communities. This is ensured by producing graduates with the key competencies of being compassionate healthcare workers who communicate well with patients from various cultural backgrounds, being able to collaborate with other health professionals in patient management, and being leaders as agents of change. Undergraduate student health professionals from multiple disciplines can improve the health outcomes of communities through contextualised health-promotion initiatives, by collaborating with each other in an interprofessional team approach. 
The discipline of dentistry in the UKZN School of Health Sciences offers a 3 -year degree in dental therapy and a 2-year diploma in oral hygiene, which is currently being replaced with a 3-year oral hygiene degree. The scope of practice for a dental therapist is preventive and curative oral healthcare, by means of various procedures such as dental examinations, diagnosis of common oral diseases, scaling and polishing, placement of direct restorations and tooth extractions. The dental therapist is well suited to meet the oral health needs of the population in both the public and private sectors and in urban and rural communities. In the public sector, the dental therapist can contribute significantly to improved oral healthcare in primary healthcare settings through oral health education and promotion, and managing oral diseases. By collaborating with other health professionals, (s)he can contribute to improved overall health outcomes in communities, through joint oral health and general health education and promotion, referrals, responding to treatment requests, teaching people about precautions and early detection of oral and systemic diseases. ${ }^{[4]}$ This collaboration needs to be fostered while the dental therapy student is in training, emphasising the need for IPE. This study aims to explore opportunities for dental therapy students' participation in collaborative interprofessional, community-based initiatives within the School of Health Sciences, UKZN.

\section{Methods}

\section{Research setting and context}

The College of Health Sciences at UKZN has four schools: clinical medicine, laboratory medicine and medical sciences, health sciences, and nursing and public health. The School of Health Sciences is made up of eight disciplines: audiology; biokinetics, exercise and leisure sciences; dentistry; occupational therapy; optometry; pharmaceutical sciences; physiotherapy; and speech language pathology. Clinical training in these disciplines occurs at campus clinics and designated off-campus sites, such as the oral and dental training site in a local hospital. Community-based education (CBE) at undergraduate level is a prominent feature across all the disciplines, although levels of participation vary. CBE activities include health awareness programmes, screenings and service delivery under supervision at local primary healthcare centres and hospitals, as well as clinical training at decentralised training sites such as regional and district hospitals. At the decentralised sites, students have an extended stay, providing a continuum of care to patients over a period of $2-6$ weeks, depending on the requirements of each discipline. Interprofessional community-based activities occur through collaboration between some disciplines, but have thus far excluded the discipline of dentistry.

\section{Research design}

This was a qualitative exploratory study in which opportunities for interprofessional community-based initiatives for dental therapy students in the UKZN School of Health Sciences were investigated by engaging with academics involved with CBE. This study was part of a larger research project conducted on CBE in the School of Health Sciences. Ethical approval was obtained from the Humanities and Social Sciences Research Ethics Committee, UKZN (ref. no. HSS/1060/015D).

\section{Participants}

The researcher used a purposive sampling method to select the study sample of academics, who were selected for their expert opinions. They included the College Dean of Teaching and Learning, the school's Academic Leader: Teaching and Learning, an academic from Family Medicine/Rural Medicine who is involved in the community-based training of medical students and an academic from the discipline of dentistry who is the head of the Professional Board for Dental Therapists and Oral Hygienists in the Health Professions Council of SA. An email invitation was sent to each person to request their participation in the study, by interview. In addition, emails were sent to the academic leaders of each of the eight health sciences programmes, requesting that they nominate one academic currently involved with $\mathrm{CBE}$ to participate in a focus-group discussion. Individual emails were sent to the nominated academics requesting their participation. Thus a total of twelve respondents (A1 - A12) agreed to participate in the study (Table 1). All provided written informed consent.

\section{Data collection}

The data were collected using both face-to-face individual interviews lasting $\sim 30$ minutes, and focus-group discussions. The researcher conducted interviews with the dean and academic leader to gain a deeper understanding of how interprofessional CBE could be implemented within the school, using a set of mainly open-ended questions to elicit qualitative information. The questions related to the policies and procedures for implementing interprofessional $\mathrm{CBE}$, associated support and mechanisms and funding for interprofessional projects. An interview was held with an academic from the Department of Family Medicine to learn how CBE was conducted in other schools within the College of Health Sciences. The researcher conducted the final interview with the academic who heads the Professional Board for Dental Therapy and Oral Hygiene on the HPCSA to gain insight into the HPCSA guidelines regarding interprofessional training for dental therapy These four interviews were scheduled at the interviewees' convenience.

In addition, the researcher facilitated two focus-group discussions with the academics representing each of the eight disciplines, with four participants in each group, as all academics could not avail themselves at once. The researcher developed a set of questions on participants' views regarding interprofessional $\mathrm{CBE}$ to guide the focus-group discussions. Sample questions included: 'What are some of the interdisciplinary collaborative activities that you are aware of that are being conducted within the School of Health Sciences?' 'What are the opportunities for dental therapy students working collaboratively with other student health professionals to enhance student training within the school?' and 'What are the possible barriers perceived to this collaboration?'

The interviews and focus-group discussions were audiotaped, and a research assistant transcribed them verbatim and then edited the language.

\begin{tabular}{|c|c|c|}
\hline Participant & Role in academia & Research method \\
\hline A1 & $\begin{array}{l}\text { Dean of Teaching and Learning in } \\
\text { College }\end{array}$ & Interview \\
\hline A2 & $\begin{array}{l}\text { Academic Leader: Teaching and } \\
\text { Learning in School }\end{array}$ & Interview \\
\hline A3 & Academic from Family Medicine & Interview \\
\hline A4 & HPCSA representative & Interview \\
\hline A5-A12 & $\begin{array}{l}\text { Focus-group participants from } \\
\text { School of Health Sciences }\end{array}$ & Two focus groups \\
\hline
\end{tabular}


The researcher engaged the services of a research consultant to assist with the data analysis process. Data coding was done by both the researcher and the research consultant to identify particular features of the data, which were then sorted, allowing themes and subthemes to emerge from the respondents' statements, in accordance with Braun and Clarke's guide to thematic analysis. ${ }^{[9]}$

Credibility is a form of internal validity in qualitative research that establishes whether the research findings are genuine and are indeed a true reflection of the participants' original views. ${ }^{[10]}$ In this study, credibility was established through the use of varied research methods, namely interviews and focus-group discussions, to collect the data. Three of the interviewees (A1, A2 and A3) were asked the same questions, while A4 was asked about the HPCSA guidelines, and A5 - A12 were asked questions about opportunities for and possible barriers to IPE implementation. Credibility was further established through peer debriefing, which was undertaken by another member of the research team, who reviewed the data collection methods and processes, transcripts and data analysis procedures, and provided guidance to enhance the quality of the research findings. ${ }^{[10]}$

Transferability relates to external validity in qualitative research, which determines the degree to which the research findings can be transferred to other contexts and other respondents. ${ }^{[10]}$ This was facilitated through the use of purposive sampling and by providing a thick description of the context of the enquiry. ${ }^{[10]}$ Transferability was further enhanced by comparing the research findings with the current literature.

Dependability is used to determine whether the same research findings would be achieved consistently if the same participants had been used in the same context. ${ }^{[10]}$ This was achieved through the use of member checks, where the analysed data were sent to a few participants to evaluate the interpretations made by the researcher. Dependability was further enhanced by both the researcher and the research consultant, as a co-coder, analysing the same data and comparing their results.

Establishing confirmability means checking that the findings are derived solely from data from participants, and not just made up by the researcher. ${ }^{[10]}$ This was established through using direct quotations of the interviewees' actual dialogue. Participant confidentiality and anonymity were maintained through the use of codenames to protect the identity of each participant (A1 - A12).

\section{Results}

Based on the responses of the interviewees, and the focus group discussions, four main themes emerged from the data analysis process: implementing IPE; the benefits of IPE; opportunities for dental therapy students' participation; and barriers to implementation.

\section{Theme 1: Implementing IPE}

Under this theme, three issues arose: the need for IPE; how IPE should be implemented; and when IPE should be implemented.

\section{The need for IPE implementation}

The focus group participants reported that they only knew of one interprofessional collaboration within the school, which involved occupational therapy, audiology, speech language pathology, physiotherapy and biokinetics. This project was initiated through a collaboration of academics from the respective disciplines. Given this context, all respondents agreed that there was a definite need for interdisciplinary education in the school (Table 2).

\section{How IPE implementation should occur}

Some of the respondents' ideas on how IPE should be implemented are given in Table 3.

\section{When IPE should be implemented}

The academics believed that IPE should have a strategic entry point, as illustrated by the quote: 'I think level one; if you do it as early as possible, then students get to know and to learn.' (A2)

\section{Theme 2: Benefits of IPE}

Respondents from the focus group recognised the value of different disciplines working together. The academics stated that IPE not only exposes students to the knowledge and skills of their own profession, but also those of others, and that by understanding the scope of practice of other professionals, they could learn to refer patients appropriately in the future (Table 4).

\section{Theme 3: Opportunities for dental therapy student participation in IPE}

The respondents indicated that there were many opportunities for dental student participation in CBE projects, including integrating oral health into general health-promotion strategies in schools and at primary healthcare centres (Table 5).

\section{Theme 4: Barriers to collaboration in implementing IPE} Academics noted a number of barriers to implementing IPE (Table 6).

\section{Discussion}

This section discusses the findings for each of the four themes: implementing IPE, benefits of collaboration, opportunities for dental therapy students' participation and barriers to implementing IPE.

Table 2. The need for IPE implementation in the School of Health Sciences

\begin{tabular}{ll}
\hline Subtheme & Participant's response \\
\hline $\begin{array}{l}\text { Inclusive planning for service-based learning } \\
\text { Student training aligned to graduate competency }\end{array}$ & $\begin{array}{l}\text { 'I think that there is a need for a definite school strategy to come to the fore.' (A2) } \\
\text { 'If we want to work in inter-, multi- or transdisciplinary teams later, we need to train in that, you need } \\
\text { to have experiences as part of your training as how you work so you get the skills.' (A3) } \\
\text { 'Tearning as contextualised in real-world settings }\end{array}$ \\
$\begin{array}{ll}\text { 'There is a demand out there and sometimes you are left alone to manage an array of conditions of } \\
\text { patients and sometimes there [are] no occupational therapists, for instance. I feel we need to do enough } \\
\text { to be able to do the basics or refer at the right point in time.' (A11) }\end{array}$ \\
\end{tabular}


Table 3. How IPE implementation should occur

\begin{tabular}{ll}
\hline Idea & Response \\
\hline Integration into existing timetables & $\begin{array}{l}\text { 'I think in health sciences it is very easy to integrate it because we already do clinical placements in } \\
\text { all of our programmes. It is not like we have to go and reinvent, getting placements fitting it into the } \\
\text { timetable, the structure is there, we basically have it'. (A1) }\end{array}$ \\
'The ideal would be to have a mobile clinic or a clinic unit where students are actually able to rotate \\
with the patient. The patient walks in, is assessed in an assessment room by a number of practitioners \\
at the same time, so you will have for example your speech and hearing person, eye specialists, your \\
dental person all assessing the patient in the presence of each other and thereafter referring the patient \\
to the specialist discipline that the patient requires.' (A4) \\
'Having an interdisciplinary clinic on campus. We can have a clinic where we all have sessions on a \\
Friday from 08h00 to 13h00 where each discipline is represented. A patient can go through a system \\
having being exposed to the different disciplines in one healthcare setting. That becomes our own \\
campus training model and when they go out there they know how to work together.' (A9)
\end{tabular}

\section{Table 4. Benefits of IPE}

\begin{tabular}{|c|c|}
\hline Benefit & Response \\
\hline Peer-assisted learning & $\begin{array}{l}\text { 'The students learn so much from each other, about each other and about the professions and that is a model for how } \\
\text { they are going to be working out there.' (A5) } \\
\text { 'Sharing of knowledge and skills and also they start to treat the patients as a whole, not in parts.' (A6) }\end{array}$ \\
\hline Knowledge of referral patterns & $\begin{array}{l}\text { 'Students are aware of the capabilities of the tasks of the scopes of practice of other types of practitioners so that they } \\
\text { are able to refer patients and that actually leads to the holistic treatment of patients.' (A4) }\end{array}$ \\
\hline Access to healthcare & $\begin{array}{l}\text { 'It will contribute immensely to community upliftment - this will improve access to different aspects of healthcare that } \\
\text { they were not introduced to previously'. (A8) }\end{array}$ \\
\hline Acquisition of non-technical skills & 'Sharing of resources.' (A6) \\
\hline & 'Problem-solving is much better with the team.' (A6) \\
\hline
\end{tabular}

\section{Table 5. Opportunities for dental therapy student participation in IPE}

Subtheme
Integrating oral health into general health

Response

'Oral health is really very well placed. It actually fits in very well with the primary healthcare, re-engineering primary healthcare and community-based training because especially if it is primary care and preventative and promotion with the school health programme, it actually fits in very well, so it resonates with the national health insurance.' (A1)

Joining existing CBE programmes

Student-initiated IPE projects

Participation in school programmes

Health education and promotion activities 'Dental therapy can definitely play an important role as I have noticed a lot of children have dental problems, but we see you as a consultant for education events, not on an ongoing basis.' (A8)

'It allows for student networking - the students do the inviting. They are the agents of action. They analysed the need and approached the various disciplines to send their students.' (A8)

'The school-based team, the dental therapy students could easily come in really effectively with the speech and audio students. It is about looking at where we can come together'. (A5)

'Going to a school, working with younger kids and saying we are looking at screening, we can do vision, oral and eye maintenance together. We can look at what services are needed and then manage it so it does not become too overwhelming for patients. If we had projects like this it would be really good. We could also educate teachers on how to pick up on hearing loss and tooth problems.' (A6)

'The clinic sites that we go to, we go into the queues, while the moms are there for the immunisation for their babies, go through these are the risk factors, we give them pamphlets. You could do that in their space. It is a captive audience there; basically they do not want to leave the queues to come for the actual testing. We say to students, they make these huge posters and they go and stand in the front, while you are waiting, nobody has to move.' (A6).

Being part of a rehabilitation team

'They also have support groups and they put people together either with different disabilities or stroke groups. So it is beyond the prevention and promotion, it is also towards development, collaboration.' (A6) 'Rehab and long term, at the moment we are seeing a lot of stroke patients, there's pooling of food, poor dentition, etc., so there is a role for dental therapy.' (A8) 
Table 6. Barriers to implementation of IPE

\begin{tabular}{|c|c|}
\hline Theme & Response \\
\hline Silo teaching & $\begin{array}{l}\text { 'There is no overall curriculum design that allows you to co-ordinate time when students are able to spend time together. } \\
\text { Some disciplines have this block system of } 2 \text { weeks and others blocks of } 5 \text { weeks and other blocks of } 6 \text { weeks so the } \\
\text { timing of us all going together to do [an] activity, which would need to be continuous over time, does not fit into every } \\
\text { curriculum.' (A3) }\end{array}$ \\
\hline Mismatch in student numbers & $\begin{array}{l}\text { 'If we have } 400 \text { medical students and we want every single one of them to have a meaningful experience with a physio, OT, } \\
\text { speech therapist, the dentist but you have only got } 30 \text { dental therapists. How do you match the numbers?' (A3) }\end{array}$ \\
\hline Non-compliance of staff & $\begin{array}{l}\text { 'A lot of people are just happy to sit in their offices and keep doing what they have been doing for the past } 15-20 \text { years, } \\
\text { because they do not see the value. To them it is just a complication, everything is working. We have been doing it this way } \\
\text { and it is working, now why are you coming to change things?' (A9) }\end{array}$ \\
\hline Lack of academic transformation & $\begin{array}{l}\text { 'It is like you want to protect your own territory, you do not realise you can learn from each other and that there is so } \\
\text { much growth. We need to transform ... it has been a culture of this university that everybody stays in their silos, we need } \\
\text { to start working together. (A11) }\end{array}$ \\
\hline Community acceptance & 'Suddenly they see this team working but they are used to seeing the doctor on their own. It causes a lot of mistrust.' (A6) \\
\hline
\end{tabular}

\section{Theme 1: Implementing IPE}

Given the context of needing to produce more socially accountable and relevant healthcare workers, the participants indicated their support for disciplines to create interprofessional learning opportunities for students. The experience of working together with other student health professionals while in training will prepare them for more effective collaborative practice in response to health needs when they graduate. Such initiatives are expected to be driven by interested academics from various disciplines, with no formal mandates from the School of Health Sciences to ensure that this takes place as a learning opportunity. The current IPE project was initiated by lecturers who are drivers in their disciplines, being motivated to transform health professionals' education and ensure that their students are equipped for various work environments. These lecturers serve as bottom-up drivers for change, having identified a need to make their teaching relevant, which should be noted by management structures that give direction in preparing the school's graduates. Drivers may be either top-down or bottom-up. ${ }^{[11]}$ Top-down drivers refers to people with the highest rank in an organisational structure directing the change. This includes leaders at universities, such as deans. Bottom-up drivers are interested academics from across multiple disciplines engaged in co-operative creating, planning and implementation to bring about transformation. ${ }^{[11]}$ In the literature, Treadwell and Havenga ${ }^{[12]}$ also note that in the absence of top-down drivers for the implementation of IPE, lecturers interested in transforming health professionals' education must serve as bottom-up drivers for change. Moreover, documented examples exist where students have identified the need to create collaborative interprofessional learning environments for themselves, having recognised that this was lacking in their education. ${ }^{[13]}$

The study showed that academics had a number of ideas of how IPE could be implemented in the school, one being to integrate IPE into the current curriculum and time-tables. However, integrating IPE into an existing curriculum can be challenging with the selection of disciplines to collaborate with being a complex process. ${ }^{[12]}$ Purden et al. ${ }^{[14]}$ in Treadwell note the complexities of such initiatives, and advocate the collaboration of not more than four disciplines. ${ }^{[12]}$

Academics believe that IPE should be implemented early in the academic programme. This is supported by VanderWielden, ${ }^{[13]}$ who recommends exposing students to IPE early in their education and training, as it offers increased opportunities for student interaction and collaboration with other emerging health professionals. Its early introduction is recommended as it takes a long time to develop the necessary skills and professional competence and to learn how to work with each other, and reap the benefits of a team approach.

\section{Theme 2: Benefits of collaboration}

The respondents reported that there were many advantages to IPE, including the fact that it exposes students to the knowledge and skills not only of their own profession, but other professions too. The respondents stated that this fosters mutual respect, trust and appreciation for other health professionals, and reduces stereotyping and assumptions about others' roles. The benefits of IPE, such as creating learning opportunities for student health professionals to acquire non-technical skills, teamwork, leadership and social accountability, are well documented in the literature. ${ }^{[12-14]}$ Another benefit is ensuring continuous, reliable and integrated care for patients. ${ }^{[13]}$

\section{Theme 3: Opportunities for dental therapy students' participation}

According to the academics in the study, there are many IPE opportunities for dental therapy students. Those involved in the existing interprofessional project were willing to allow dental therapy students to join their project for health education activities, where they could contribute significantly in terms of oral health education for children in the community, as well as offer preventive measures such as fissure sealants and tooth-brushing programmes. This can be seen as an opportunity to screen children for dental problems, offer advice and refer them to the nearest clinic for the management of serious oral conditions.

In situations where 'students are doing the inviting', dental therapy students could become proactive and liaise with students from other disciplines involved with the project, and also become 'agents of action' This is supported by the literature, which draws attention to student-led IPE programmes among student health professionals in the USA, where they recognised interprofessional training as a valuable, but missing, learning strategy in their education. ${ }^{[13]}$ This fostered networking, which is a key component of interprofessional collaboration and developing relationships 
that could benefit current education and future patient care. ${ }^{[13]}$ The literature shows that because oral diseases and other NCDs share common risk factors, integrating oral health promotion strategies and programmes with programmes in the prevention and control of NCDs can lead to better health outcomes. ${ }^{[8]}$ This can be implemented using the settings approach.

\section{The settings approach}

The settings approach used in health-promotion initiatives creates opportunities to address relevant health issues in the contexts in which people live, work and play. ${ }^{[15]}$ This approach is widely advocated and yields considerable success, as it organises health-promotion interventions to target specific health problems relevant to specific communities. ${ }^{[15]}$ In this study, the respondents agreed that this approach can be used for collaborative initiatives, and identified two relevant settings - the school and the primary healthcare setting.

School setting: The academics in the focus groups suggested that dental therapy students could fit into an interprofessional team that could go to schools where joint oral health and health education programmes, health promotion and screenings could be conducted. Such activities conducted in the school setting have been identified as the most creative and cost-effective way to improve general health, oral health and quality of life. ${ }^{[16]}$ Reddy and Singh $^{[17]}$ noted an increased awareness among learners and educators of the importance of daily tooth brushing and adopting the correct tooth-brushing techniques following oral health education interventions conducted in schools, especially in rural areas. It was further noted that following oral health promotion interventions, learners realised the importance of correct eating habits that could inform their choice of purchases from tuck shops and vendors. ${ }^{[17]}$

Primary healthcare setting: The academics cited primary healthcare settings as another opportunity for interprofessional collaboration for combined oral health and general health promotion initiatives. These could take the form of health education talks, as suggested by the academics, while patients are waiting to be treated. Dental therapy students working together with other health professional students would foster the integration of oral health into general health more effectively, and improve oral healthcare in communities. ${ }^{[18]}$ Treadwell and Havenga ${ }^{[12]}$ have noted that setting the scene and creating the situation is crucial in the actual learning that takes place. Thus, by using the settings approach, students would be exposed to real world settings in which they learn to contextualise, design and implement promotion inventions within resource and funding constraints, this being different from when they will do so at the ideal training sites of their institution.

\section{The team approach for rehabilitation}

Besides collaborating in prevention and promotion activities, opportunities also exist for dental therapy students to participate collaboratively with other health professional students in the rehabilitation of patients with physical disabilities, and stroke patients. A stroke can have major effects on oral and facial soft tissues, and can affect simple oral functions such as chewing, drinking and swallowing. ${ }^{[19]}$ In addition, moving the tongue towards the affected side results in food pooling in that side of the mouth and reduces oral clearance, which increases the risk of dental caries, periodontal diseases and halitosis. ${ }^{[19]}$ Moreover, medications used to treat stroke patients can result in xerostomia (dry mouth), which further increases the risk of dental caries. ${ }^{[19]}$ Oral healthcare is therefore important for stroke patients, but is often overlooked during the rehabilitation phase. The team that manages a stroke patient usually consists of physiotherapists, occupational therapists and speech language therapists, with dental personnel not included. In order for changes to occur in the healthcare workplace regarding professional collaboration, transformation must occur at the level of training. Student health professionals from these disciplines, together with dental therapy students, should be given learning opportunities to work together in the rehabilitation of stroke patients. This could lead to better health outcomes for the patient, as well as encouraging the general inclusion of dental therapists in the rehabilitation team.

In a systematic review of strategies used for IPE activities, it was observed that the most common strategy used by universities was holding small group discussions, followed by case- or problem-based learning, clinical teaching or direct interaction with patients, simulations, community-based education projects and e-learning. ${ }^{[20]}$ It is clear from the focus-group discussions that there are diverse interprofessional learning opportunities for dental therapy students. These opportunities include joint oral and general health education and promotion activities, screening programmes, diagnosis and referral of patients and rehabilitating patients with stroke and physical disabilities. These opportunities resonate with the principles of primary healthcare, namely prevention, promotion, curative care and rehabilitation, thus establishing a link between IPE and PHC and providing the most appropriate mode for facilitating IPE for dental therapy students.

\section{Theme 4: Barriers to IPE}

The main barriers to IPE identified in this study were finding a common time for the students from the different disciplines to participate in IPE activities, matching the numbers of students and a lack of staff co-operation. Abu-Rish et al., ${ }^{[20]}$ in a systematic review of IPE, also reported similar barriers across 65 studies, such as scheduling a common time for IPE implementation, difficulties in matching numbers of students with similar backgrounds, skills and levels of clinical knowledge, funding, and staff and leadership buy-in. To overcome some of the barriers experienced at UKZN, the academics made the following recommendations:

'We can start by aligning the sites, opening up communication and start talking to each other.' (A11)

'There is huge opportunity to sit and develop either a common module or say these are going to be the common times for all of us even if you keep your own separate modules.' (A5)

'You need a phased-in approach to implement such a programme. Just getting the buy-in from everybody that will be involved at every stage in the academic progress.' (A11)

'We should bring innovation and change and ourselves be trained in the very same field. We do not know it at all so we should be open to get more knowledge about what is happening elsewhere.' (A10)

Getting the co-operation of staff is challenging; however, Treadwell and Havenga ${ }^{[12]}$ recommend that staff engage in collaborative discussions to develop a shared understanding of the purpose and goals of IPE, to bring about changes in thinking and acceptance.

\section{The way forward}

The study findings indicate that dental therapy students are well suited 
to collaborate with those from the other disciplines. The IPE strategy best suited for their inclusion is engaging in community-based disease prevention and health-promotion interventions, as oral health is related to general health and wellbeing. As a suggestion, it may be a good idea to start a collaboration with one other discipline initially, by integrating oral health promotion into general health-promotion programmes, which can be presented together in primary healthcare settings or school settings. Once the basic logistics have been addressed, other disciplines can be incorporated, depending on how the dental therapy student participation integrates with their curricula and clinical placements.

Most of the disciplines in the UKZN School of Health Sciences send students to decentralised sites for work experience, which is an untapped opportunity for student health professionals to engage with each other, network, collaborate and conduct contextualised health-promotion interventions with patients throughout the hospital while patients are waiting to be attended to. A programme could be devised whereby the students start off their day by working collaboratively, after which they work in their respective departments attending to their patients.

IPE is an effective pedagogical approach that allows health professions students to gain a better understanding of the roles of other professions, as well as collaborative skills. ${ }^{[21]}$ Universities have an important role to play in creating such learning opportunities, their implementation requiring motivated drivers of change who can initiate this process of transformation. In this study, it was noted that academics from the various disciplines were the drivers in creating and implementing IPE interventions. Academics should embrace this opportunity to meet, collaborate and plan IPE activities for student health professionals. However, successful implementation requires more than just drivers - it requires supportive leadership, committed academics and student compliance.

\section{Study limitations}

It is acknowledged that this study was limited to a single university, making the findings and their context limited in their generalisability. More research is therefore required at other universities in SA that train dentistry, dental therapy and oral hygiene students, to obtain a better understanding of how IPE opportunities could be created and incorporated into their programmes.

\section{Conclusion}

The study findings revealed that opportunities do exist for interprofessional community-based education for dental therapy students. Using the settings approach, the Discipline of Dentistry undergraduates, in collaboration with other student health professionals, can conduct health-promotion interventions that are contextualised for specific communities, depending on their needs and the available resources, in school, primary healthcare and other community-based settings. Using a team approach, they can be included in student healthcare teams that are involved with screening, diagnosis and referral systems, as well as in rehabilitating patients. However, the creation of interprofessional interventions requires individual lecturers from the various disciplines to act as drivers in consultation with each other, with support from programme managers to support curriculum changes and resource allocations. To ensure that the students are equipped to participate in team collaborations once they enter the work environment, the School also needs to support and motivate for such collaborations during training.

\section{Acknowledgements. None.}

Author contributions. IM was responsible for data collection, data analysis and conceptualisation. SS was responsible for refining the methodology and overseeing the write-up.

Funding. None,

Conflicts of interest. None.

1. Frenk J, Lincoln C, Zulfigar A, et al. Health professionals for a new century: Transforming education to strengthen health systems in an interdependent world. Lancet 2010; 376(9756): 1923-1958. https://doi.org/10.1016/s01406736(11)(60492)

2. World Health Organization. Report on a WHO study group on multiprofessional education of health personnel: The team approach. Technical report series 769. Geneva: WHO, 1988. http://apps.who.int/iris handle/10665/37411 (accessed 10 September 2014)

3. Barr H, Koppel I, Reeves S, et al. Effective interprofessional education: Argument, assumption and evidence. Oxford: Blackwell Publishing, 2005.

4. Wilder RS, O’Donnell JA, Barry JM et al. Is dentistry at risk? A case for interprofessional education. J Denta Educ 2008; $72(11): 1231-1237$.

5. Petersen PE. The World Oral Health Report 2003: Continuous improvement of oral health in the 21st century the approach of the WHO Global Oral Health Programme. Geneva: World Health Organization, 2003.

6. Sheiham A, Watt R. The common risk factor approach: A rational basis for promoting oral health Community Dent Oral Epidemiol 2000;28(6):399-406. https:/doi.org/10.1034/j.1600-05 28,2000.028006399 x

7. Global Action Plan for the Prevention and Control of Non-communicable Diseases. 2013-2020. Geneva: World Health Organization, 2013. www.who.int/iris/bitstream/10665/943384/1/9789241506236 (accessed 4 September 2014).

. Department of Health, South Africa. Annual Health Report 2013/2014. Pretoria: NDoH, 2014

9. Braun V, Clarke V. Using thematic analysis in psychology. Qual Res Psychol 2006;3(2):77-101. https://doi org $/ 10.1191 / 1478088706 q p 0630 a$

0. Anney, VN. Ensuring the quality of the findings of qualitative research: Looking at trustworthiness criteria Journal of Emerging Trends in Educational Research and Policy Studies 2014;5(2):272-281.

11. VanderWielen LM, Do EK, Diallo HI et al. Interprofessional collaboration led by health professional students: A case study of the Inter Health Professional Alliance of Virginia Commonwealth University. J Res Interprof Pract Educ 2014;3(3):1-13. https://doi.org/10.22230/jripe.2014v3n3a132

12. Treadwell I, Havenga HS. Ten key elements for implementing interprofessional learning in clinical simulations. Afr J Health Professions Educ 2013;5(2):80-83. https://doi.org/10.7196/ajhpe.233

13. VanderWielen L, Enurah A, Osburn I. The development of student-led interprofessional education and collaboration. J Interprof Care 2013;(0):1-2. https://doi.org/10.3109/13561820.2013.790882

14. Purden $\mathrm{M}$, Fletscher D, Ezer $\mathrm{H}$, et al. The McGill Educational Initiative on Interprofessional Collaboration: Partnerships for patient and family-centred practice.http://wwwinterprofessionalcare.mcgill.ca/projectoverview. htm (accessed 21 March 2018).

15. Poland B, Krupa G, McCall D. Settings for health promotion: An analytic framework to guide interventions design Poland B, Krupa G, McCall D. Settings for health promotion: An analytic framework to guide interventions desig
and implementation. Health Promotion Pract 2009;10(4):505-516. https://doi.org/10.1177/1524839909341025 and implementation. Health Promotion Pract 2009;10(4):505-516. https://doi.org/10.1177/1524839909341025
6. Petersen P. Challenges to improvement of oral health in the 21st century - the approach of the WHO Global 6. Petersen P. Challenges to improvement of oral health in the 21st century - the approach of the WHO Global
Oral Health Programme. Internat Dental J 2004;54(S6):S329-S343. https://doi.org/10.1111/j.1875-595x.2004. Oral Health Programme. Internat Dental J 2004;54(S6):S329-S343. https://doi.org/10.1111/j.1875-595x.2004. tb00009.x

17. Reddy M, Singh S. The promotion of oral health in health-promoting schools in KwaZulu-Natal, South Africa. S Afr J Child Health 2017;11(1):16-20. https://doi.org/10.7196/SAJCH.2017.v1 1i1.1132

18. Rhoda A, Lattoe N, Smithdorf G, et al. Facilitating community-based interprofessional education and collaborative practice in a health science faculty: Student perceptions and experiences. Afr J Health Profession Educ 2016;8(S2):S225-S228

19. Fatahzadeh M, Glick M. Stroke: Epidemiology, classification, risk factors, complications, diagnosis, prevention, and medical and dental management. Oral Surg Oral Med Oral Pathol Oral Radiol 2006;102(2):180-191. https:// doi.org/10.1016/j.tripleo.2005.07.031

20. Abu-Rish E, Kim S, Choe L, et al. Current trends in interprofessional education of health sciences students: A literature review. J Interprof Care 2012;26(6):444-451. https://doi.org/10.3109/13561820.2012.715604

21. Hammick M. Freeth D, Koppel I, et al. A best evidence systematic review of interprofessional education: BEME Guide No. 9. Med Teach 2007;29(8):735-751. https://doiorg/10.1080/01421590701682576 